\title{
Survival Mechanism of Puccinia abrupta var.partheniicola Urediniospores During Summer Season
}

\author{
MOHAMAD TAUFIK FAUZI

\begin{abstract}
Faculty of Agriculture, Universitas Mataram, Jalan Majapahit 62, Mataram 83125, Nusa Tenggara Barat, Indonesia
\end{abstract} \\ Phone/Fax: +62-370-640744, Email:taufikfz@telkom.net
}

\begin{abstract}
The success of applying plant pathogens as biological control agents of weeds relies on the ability of the biological control agent to persist at all parts of the year and to successfully go through all of its life cycle stages in the course of a single year. One important aspect of any plant disease life cycle is the ability to survive during unfavorable parts of the season. The research aimed at understanding the mechanism involved in the survival of Puccinia abrupta var. partheniicola, a potential biological control agent of parthenium weed (Parthenium hysterophorus), during simulated summer conditions had been undertaken in the field plot at the Alan Fletcher Research Station, Brisbane. The urediniospores that were placed either on plant debris or on intact plants were exposed to summer conditions and were regularly tested their viability after being exposed. The results showed that the urediniospores could only survive for less than six weeks, which is less than half of the Queensland summer where the weed is abundant. This indicates that the rust spores do not survive on infected parthenium weed debris during summer season.
\end{abstract}

Key words: Survival, Puccinia abrupta var. partheniicola, biological control of weeds

The strategy used in implementing the rust Puccinia abrupta var. partheniicola, a potential biological control agent of parthenium weed (Parthenium hysterophorus L.), a very troublesome weed of agricultural areas in tropical and sub tropical regions such as Australia, India, Taiwan, Vietnam and China, onto the weed is commonly referred to as 'classical' (TeBeest et al. 1992). In this strategy, the establishment of the disease depends solely on the innate ability of the plant pathogen to establish (survive) and then to disperse. The success of this approach therefore relies on the ability of the biological control agent to persist at all parts of the year and to successfully go through all of its life cycle stages in the course of a single year. One important aspect of any plant disease life cycle is the ability to survive during unfavorable parts of the season, for example, soil-borne urediniospores of Puccinia recondita Rob. f.sp. tritici Erics., the causal agent of leaf rust on wheat (Triticum aestivum L.) are able to over summer on volunteer wheat plants and therefore are able to serve as a source of inoculums for the primary infection on autumn sown wheat (Hassan et al. 1986). The survival of rust pathogenic biocontrol agents during adverse season (summer or winter) may well be on infected plant debris.

The survival strategy of Puccinia abrupt var. partheniicola a macrocyclic and autoecious rust, in the central Queensland summer is unknown. However, since the rust's teliospores do not germinate under normal field conditions (Evans 1987), it is believed that this rust may survive by means of its urediniospores produced in an asexual life cycle phase. Such spore may then remain on plant debris or in the soil.

The objective of the present study was to determine whether the rust usediniospores could oversummer on the parthenium weed host or its debris under simulated Queensland summer conditions.

\section{MATERIALS AND METHODS}

Summer Survival of Spores on Plant Debris. Parthenium weed seeds collected from plants growing in the Clermont region of central Queensland were sown to a depth of $1 \mathrm{~cm}$ in seedling trays containing a peat and sand $(1: 3 ; \mathrm{v} / \mathrm{v})$ potting compost enriched with complete fertilizer. The compost was then wetted to field capacity with tap water and placed in a glasshouse at $30 / 26 \pm 5^{\circ} \mathrm{C}$ (day/night). When the seedlings were 10 days old they were transplanted to $20 \mathrm{~cm}$ diameter pots (one plant per pot) containing the same potting compost as described above. Six-weeks-old parthenium weed plants were inoculated with the solution of urediniospores in $1 \mathrm{~L}$ sterile distilled water containing two drops of Tween 20 at the rate of 20000 spores $\mathrm{mL}^{-1}$ as determined using a haemocytometer. Each plant was inoculated with $10 \mathrm{~mL}$ urediniospore solution using a Wattyl Jet-Pack spray unit (Wattyl Australia Pty., Canada Bay, NSW). The inoculated plants were then individually covered with previously misted (with distilled water), black plastic bag and placed in a dark growth chamber at $15 \pm 1{ }^{\circ} \mathrm{C}$ for $12 \mathrm{~h}$. After this, the plastic bags were removed and the plants were placed in naturallylit glasshouse with a day/night temperature regime of $32 / 25$ $\pm 5{ }^{\circ} \mathrm{C}$. The first symptoms of the rust disease appeared 10 days after inoculation. Three weeks after the first symptom appeared, leaves had become heavily infected with the rust. Infected leaves from some of the plants were removed and enclosed in $10 \times 10 \mathrm{~cm}^{2}$ packet consisting of plastic mesh (sold as insect screen by Kmart Pty Ltd., Brisbane). These packets containing the infected leaves were then placed on the soil surface or hung on sticks $1 \mathrm{~m}$ above the soil surface in field plot at the Alan Fletcher Research Station (AFRS), Brisbane. A final treatment consisted of infected leaves that had been left attached to senesced parthenium weed plants persisting on land in the same field site. The field plot in which this experiment was undertaken had been previously cleared of other form of vegetation using a knock down herbicide. The $5 \times 5 \mathrm{~m}^{2}$ field plot was fenced to the height of $150 \mathrm{~cm}$ with a thick plastic mesh.

During the course of exposure of the leaf samples in the field, samples of infected leaves or packets were removed every 2 weeks. These samples were washed lightly to remove any adhering soil, the leaves then cut into $2 \times 2 \mathrm{~cm}^{2}$ pieces 
and placed into glass beakers (one sample per beaker) containing sterile distilled water. The beakers were then shaken gently to release spores from the leaves. The water washes were then spread over the surface of a water-agar medium and urediniospore germination counted 2 days later. This germination value was taken as indication of the spore viability.

Transfer of Spores in the Summer Months. Parthenium weed plants were produced by first sowing seed onto the soil surface of a $5 \times 5 \mathrm{~m}^{2}$ fenced field plot. This plot had been prepared in the same way as in the first experiment. In addition, to these plants others were produced in $25-\mathrm{cm}$ diameter black plastic pots containing potting compost at AFRS, Brisbane. After seedling emergence and at the rosette stage of development, the plants in pot were inoculated with urediniospores. Once infection has developed, these plants were then placed in the middle of the mature healthy plants, thick growing parthenium weed stand that had been produced in the fenced field plot. Infection of some of the healthy plants was observed as soon as 3 weeks after the introduction of the infected plants. Several branches bearing newly infected leaves were then randomly tagged and monthly observation taken on the formation of new pustules over a winter to a summer period (July to February).

\section{RESULTS}

Summer Survival of Spores on Plant Debris. The viability of the urediniospores when first collected and prior to all the treatments ranged from 90 to $95 \%$. This was done by spreading newly harvested urediniospores on the surface of a water agar medium and the urediniospore germination was counted. However, upon exposure to the different treatments viability decreases at different rates (Fig 1). The lowest decrease in viability, after 2 and 4 weeks exposure, was found with urediniospores that remained on intact, but dead plants. This loss in viability (68 and $49 \%$ urediniospore germination after being exposure for 2 and 4 weeks, respectively) was lower than that seen on leaves hanging or on the soil surface. The maximum period any urediniospores survival in the southern Queensland summer was for between 4 and 6 weeks.

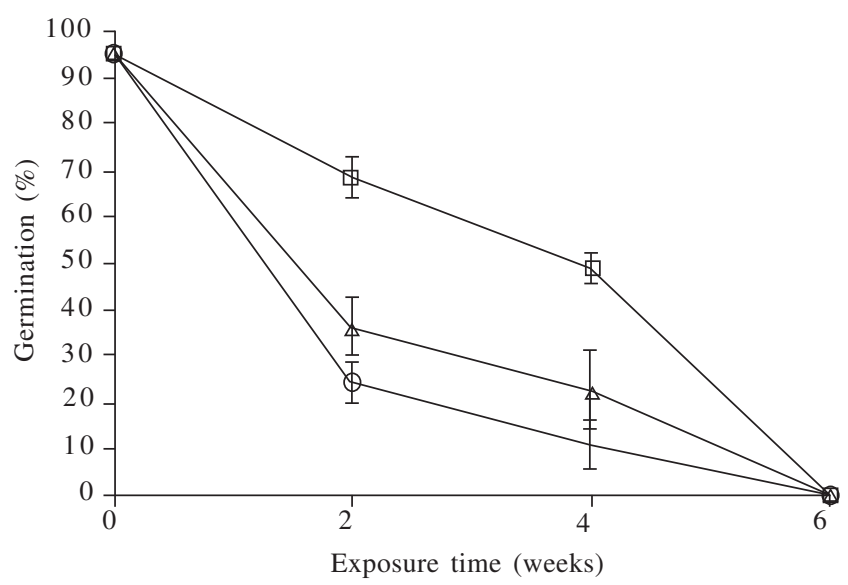

Fig 1 Field survival of $P$. abrupt var. partheniicola urediniospores exposed to southern Queensland summer conditions. Urediniospores were either on Parthenium weed plant, on leaves hanging in mesh bag, or on leaves placed in mesh bags on the soil surface. Vertical bars represent the standard deviation. $\bigcirc$, soil surface; $\square$, plant; $\Delta$, hung.
Transfer of Spores in the Summer Months. Three weeks (August) after the placement of the infected parthenium weed plants into the field plots containing the healthy parthenium weed plants, transfer of spore took place. A few pustules ( $>5$ pustules per tagged branch) were observed on few previously healthy plants within several days. The number of new pustules forming was decreased as the summer temperature increased, three to five pustules developing in September, while only one pustule developed in October and November. The size of these newly formed pustules in the warmer months was also smaller than those formed earlier. No new pustules were observed on plants in December through February when the experiment was terminated.

\section{DISCUSSION}

The use of intact parthenium weed plants or their leaf debris in the present urediniospore survival study was based on the idea that $P$. abrupt var. partheniicola is an autoecious rust (Parmelee 1967; Evans 1987), able to complete its life cycle on just one host. This view suggests that the rust must survive, at all times of the year, on the weed host or in its debris and not on a secondary host. Even though resting body spores (teliospores) have been found on plants growing in upland areas of Mexico, they have not been noted to germinate under normal field conditions $\left(20-30{ }^{\circ} \mathrm{C}\right)$ nor have they been noted to infect parthenium plants under any conditions (Evans 1987). These observations therefore indicate that teliospores are unlikely to be a method of the rust survival in the field.

The rust urediniospores used in the present study could only survive for a very short time (between 4 and 6 weeks; Fig 1) on parthenium weed or its debris in the field during a southern Queensland summer. While a typical Queensland summer lasts for around 4 months, it seems that from the present studies that the rust urediniospores can only survive for less than half of this time. This result may due to the high temperatures during the mid summer (December to January) which could reach $30-35^{\circ} \mathrm{C}$. The urediniospores of this rust could not germinate at the incubation temperature of $30{ }^{\circ} \mathrm{C}$ (Fauzi 1998). Several rust pathogens had been reported to only survive for short period during the summer, for example, groundnut rust ( $P$. arachidis Speg.) could only survive for 20 days under the field conditions $\left(25-28^{\circ} \mathrm{C}\right)$ (Sunkad and Kulkarni 2007). Similar result had been reported on the viability of $P$. jaceae var. solstitialis, a biocontrol agent of yellow starthistle, where urediniospores only survive for two to three weeks at warm summer temperatures (Fisher et al. 2008). The field observation made by staff at the Queensland Department of Natural Resources the Alan Fletcher Research Station while working in central Queensland have also indicated that no oversummering pustules have been observed (Tomley, personal communication). The latest time that new pustules could be formed on new parthenium weed plants in the field was early summer, November. This observation made in this study is similar to that seen in the field in central Queensland where new infections are not observed from November to March (Moolayember Creek, $90 \mathrm{~km}$ south of Rolleston, central Queensland). This indicated that the parthenium rust did 
not survive on infected plant debris nor did on visible infected parthenium plants (Fig 1).

It is therefore possible that other oversummering mechanisms, not studied at present, may be those that are used by the rust's urediniospores. Such mechanisms could involve survival on plants that are growing in cooler, wetter microclimatic regions that then provide long range dispersal of spores to other regions in autumn. Such a mechanism has been seen for a yellow rust infecting wheat (Rapilly 1979). This hypothesis is unlikely for parthenium weed since the availability of plants growing in autumn in other region into which the spores are dispersed is not commonly seen in the field in central Queensland.

Another possible mechanism for oversummering is that the urediniospores survive on seed (as a seed-borne pathogen), in the soil, similar to that observed for Colletotrichum gloeosporiedes f.sp. aeschynomene which has been found to re-infest northern joint vetch (Aeschynomene virginica; TeBeest and Brumley 1978) from seed infested with C. gloeosporiodes. This survival mechanism for oversummering is unlikely to occur in the field in central Queensland since there have been no reports of newly emerged parthenium weed seedlings that are already infected. This would be expected if the seed was carrying the pathogen.

A third suggested mechanism for oversummering that is not supported by the present findings, is that the urediniospores oversummer on infected parthenium weed debris. A further possible mechanism for survival of the spores over summer involves the concept of latent infection. A latent infection mechanism is seen with the rust $P$. striiformis on wheat (Dennis 1987). Hungerford (1923) reported a similar mechanism for the rust $P$. glumorum on Elymus glaucus plants over the summer period from June to September. Adam and Line (1984) had suggested a possible involvement of a latent infection as another survival mechanism of $P$. chondrillina, a successful biocontrol agent of the rush skeleton weed (Chondrilla juncea L.), during the winter of 1979-1980 in Washington. The possible involvement of latent infections might explain the survival mechanism of the rust under study in the field. The infection of the rust urediniospores on parthenium leaves did not form any visible symptoms because of the unfavorable environmental conditions of the hot and dry summer.
However, they may have survived as mycelia on leaves, with pustules only beginning to appear when the cool autumn conditions appear. This hypothesis could be used to explain the new autumn infection of the rust $P$. abrupt var. partheniicola which only occurred on parthenium weed plants at Moolayember Creek, a site where the weed was present all the year round (Tomley, personal observation).

\section{ACKNOWLEDGEMENT}

I thank AusAid Australia for providing the scholarship to the author. I also thank Alan Fletcher Research Station, Queensland Department of Natural Resources, Brisbane for the use of the field plot, glasshouse and laboratory and other facilities for running this experiment.

\section{REFERENCES}

Adam EB, Line RF. 1984. Biology of Puccinia chondrillina in Washington. Phytopathology 74:742-5.

Dennis JL. 1987. Effect of high temperatures on survival and development of Puccinia striiformis on wheat. Trans Br Mycol Soc 88:91-6.

Evans HC. 1987. Life-cycle of Puccinia abrupta var. partheniicola, a potential biological control agent of Parthenium hysteroporus. Trans Br Mycol Soc 88:105-11.

Fauzi MT. 1998. Biological Control of Parthenium Weed by Puccinia abrupta var. partheniicola. [Ph.D. Thesis]. Brisbane: The University of Queensland.

Fisher JF, Woods DM, Smith L, Bruckart III WL. 2008. Latent period and viability of Puccinia jaceae var. solstitialis urediniospores: implication for biological control of yellow starthistle. Biol Control 45:146-53.

Hassan ZM, Kramer CL, Eversmeyer MG. 1986. Summer and winter survival of Puccinia recondita and infection by soilborne urediniospores. Trans Br Mycol Soc 86:365-72.

Hungerford CW. 1923. Studies on the life history of stripe rust, Puccinia glumarum (Schm.) Erikss \& Henn. J Agric Res 24:60720.

Parmelee JA. 1967. The autoecious species of Puccinia on Heliantheae in North America. Can J Bot 45:2267-328.

Rapilly F. 1979. Yellow rust epidemiology. Annu Rev Phytopathol 17:59-73.

Sunkad G, Kulkarni S. 2007. Studies on perpetuation and carry over of groundnut rust (Puccinia arachidis Speg.) in northern Karnataka. Karnataka J Agric Sci 20:297-300.

TeBeest DO, Brumley JM. 1978. Colletotrichum gloesporioides borne within the seed of Aeschynomene virginia. Plant Dis Rep 62:6758.

TeBeest DO, Yang XB, Cisar CR. 1992. The status of biological control of weeds with fungal pathogens. Annu Rev Phytopathol 30:637-57. 